\title{
White matter hyperintensities mediate the association between blood-brain barrier leakage and information processing speed
}

Citation for published version (APA):

Freeze, W. M., Jacobs, H. I. L., de Jong, J. J., Verheggen, I. C. M., Gronenschild, E. H. B. M., Palm, W. M., Hoff, E. I., Wardlaw, J. M., Jansen, J. F. A., Verhey, F. R., \& Backes, W. H. (2020). White matter hyperintensities mediate the association between blood-brain barrier leakage and information processing speed. Neurobiology of Aging, 85, 113-122. https://doi.org/10.1016/j.neurobiolaging.2019.09.017

Document status and date:

Published: 01/01/2020

DOI:

10.1016/j.neurobiolaging.2019.09.017

Document Version:

Publisher's PDF, also known as Version of record

\section{Document license:}

Taverne

Please check the document version of this publication:

- A submitted manuscript is the version of the article upon submission and before peer-review. There can be important differences between the submitted version and the official published version of record.

People interested in the research are advised to contact the author for the final version of the publication, or visit the DOI to the publisher's website.

- The final author version and the galley proof are versions of the publication after peer review.

- The final published version features the final layout of the paper including the volume, issue and page numbers.

Link to publication

\footnotetext{
General rights rights.

- You may freely distribute the URL identifying the publication in the public portal. please follow below link for the End User Agreement:

www.umlib.nl/taverne-license

Take down policy

If you believe that this document breaches copyright please contact us at:

repository@maastrichtuniversity.nl

providing details and we will investigate your claim.
}

Copyright and moral rights for the publications made accessible in the public portal are retained by the authors and/or other copyright owners and it is a condition of accessing publications that users recognise and abide by the legal requirements associated with these

- Users may download and print one copy of any publication from the public portal for the purpose of private study or research.

- You may not further distribute the material or use it for any profit-making activity or commercial gain

If the publication is distributed under the terms of Article $25 \mathrm{fa}$ of the Dutch Copyright Act, indicated by the "Taverne" license above, 


\title{
White matter hyperintensities mediate the association between blood-brain barrier leakage and information processing speed
}

\author{
Whitney M. Freeze ${ }^{\mathrm{a}, \mathrm{b}}$, Heidi I.L. Jacobs ${ }^{\mathrm{a}, \mathrm{c}}$, Joost J. de Jong ${ }^{\mathrm{b}}$, Inge C.M. Verheggen ${ }^{\mathrm{a}}$, \\ Ed H.B.M. Gronenschild ${ }^{\mathrm{a}}$, Walter M. Palm ${ }^{\mathrm{b}}$, Erik I. Hoff ${ }^{\mathrm{d}}$, Joanna M. Wardlaw ${ }^{\mathrm{e}}$, \\ Jacobus F.A. Jansen ${ }^{b}$, Frans R. Verhey ${ }^{a}$, Walter H. Backes ${ }^{b}$,* \\ ${ }^{a}$ Department of Psychiatry E Neuropsychology, Maastricht University, School for Mental Health E Neuroscience, Alzheimer Centre Limburg, \\ Maastricht, the Netherlands \\ ${ }^{\mathrm{b}}$ Department of Radiology \& Nuclear Medicine, Maastricht University Medical Centre, School for Mental Health E Neuroscience, Maastricht, the \\ Netherlands \\ ${ }^{\mathrm{C}}$ Division of Nuclear Medicine and Molecular Imaging, Department of Radiology, Massachusetts General Hospital, Harvard Medical School, Boston, \\ MA, USA \\ ${ }^{\mathrm{d}}$ Department of Neurology, Zuyderland Medical Centre Heerlen, Heerlen, the Netherlands \\ e Brain Research Imaging Centre, Centre for Clinical Brain Sciences and UK Dementia Research Institute at the University of Edinburgh, Edinburgh, UK
}

\section{A R T I C L E I N F O}

\section{Article history:}

Received 15 April 2019

Received in revised form 27 August 2019

Accepted 22 September 2019

Available online 27 September 2019

\section{Keywords:}

Blood-brain barrier

Cognition

Hippocampus

Small vessel disease

White matter hyperintensities

\begin{abstract}
A B S T R A C T
Blood-brain barrier (BBB) leakage is considered an important underlying process in both cerebral small vessel disease (CSVD) and Alzheimer's disease (AD). The objective of this study was to examine associations between BBB leakage, CSVD, neurodegeneration, and cognitive performance across the spectrum from normal cognition to dementia. Leakage was measured with dynamic contrast-enhanced magnetic resonance imaging in 80 older participants (normal cognition, $\mathrm{n}=32$; mild cognitive impairment, $\mathrm{n}=$ 34; clinical AD-type dementia, $\mathrm{n}=14$ ). Associations between leakage and white matter hyperintensity (WMH) volume, hippocampal volume, and cognition (information processing speed and memory performance) were examined with multivariable linear regression and mediation analyses. Leakage within the gray and white matter was positively associated with WMH volume (gray matter, $p=0.03$; white matter, $p=0.01$ ). A negative association was found between white matter BBB leakage and information processing speed performance, which was mediated by WMH volume. Leakage was not associated with hippocampal volume. WMH pathology is suggested to form a link between leakage and decline of information processing speed in older individuals with and without cognitive impairment.
\end{abstract}

(c) 2019 Elsevier Inc. All rights reserved.

\section{Introduction}

The neuropathology of Alzheimer's disease (AD) is characterized by amyloid plaques and neurofibrillary tau tangles, which both contribute to neurodegenerative processes (Jack et al., 2013). However, several neuroimaging and autopsy studies have suggested that vascular pathology in the form of cerebral small vessel disease (cSVD) also plays a significant role in the pathological AD cascade (Arvanitakis et al., 2016; Kester et al., 2014). Actually, most cases with clinical dementia have mixed AD and vascular pathology in the brain (Schneider et al., 2007). A pathological process that could link cSVD and AD is blood-brain barrier (BBB) dysfunction

\footnotetext{
* Corresponding author at: Department of Radiology \& Nuclear Medicine, School for Mental Health and Neuroscience, Maastricht University Medical Center, P.O. box 5800, 6202AZ Maastricht, the Netherlands. Tel.: +31 4338 74911; fax: +31 (0) 43 3876909.

E-mail address: w.backes@mumc.nl (W.H. Backes).
}

(Zlokovic, 2008). The BBB controls the homeostasis of the brain tissue environment, which is essential for neuronal vitality and signaling (Iadecola, 2017). Dysfunction of the BBB may lead to an illconditioned microenvironment with eventual neuronal dysfunction, tissue damage, or even cell loss.

Detailed information about localized functional BBB dysfunction can be obtained with dynamic contrast-enhanced MRI (DCE-MRI) by measuring the leakage of gadolinium contrast medium into the cerebral tissue. A number of recent studies have applied this technique to demonstrate involvement of BBB dysfunction in normal aging (Montagne et al., 2015), cSVD (Wardlaw et al., 2017; Zhang et al., 2017), mild cognitive impairment (MCI) (Montagne et al., 2015; Nation et al., 2019), and AD (van de Haar et al., 2016). These studies suggest involvement of BBB leakage in the pathophysiology of cSVD-related MRI abnormalities such as white matter hyperintensities (WMHs) (Wardlaw, 2010; Wardlaw et al., 2017) and also contributions of BBB dysfunction to early neurodegenerative 
processes associated with AD (Iturria-Medina et al., 2016; van de Haar et al., 2016). The associations between BBB dysfunction, cSVD, neurodegeneration, aging, and cognition are extremely complex and not yet well understood (Yamazaki and Kanekiyo, 2017). Further clarification of these associations is pivotal to increase our understanding of vascular contributions to dementia and to find novel diagnostic and therapeutic strategies.

The primary aim of this study was to examine links between quantitative measures of BBB dysfunction (i.e., leakage rate and volume), cSVD burden (i.e., WMH volume), neurodegeneration (i.e., hippocampal volume [HV]), and cognition in cognitively normal $(\mathrm{CN})$ individuals and memory clinic patients. The emphasis of the present study was not on individual diagnostic groups or group differences, but we rather took a continuous approach by including older individuals within the range from normal cognition to clinical dementia with variability in neurodegenerative and cSVD pathology. Because BBB dysfunction directly reflects cerebrovascular disintegrity, we (i) hypothesized that increased cSVD burden (i.e., larger WMH volume) was associated with increased BBB dysfunction in both gray and white matter (GM and WM). Because previous work suggested that BBB dysfunction is increased within the hippocampus in individuals with $\mathrm{MCI}$ (Montagne et al., 2015), we (ii) also hypothesized that neurodegeneration (i.e., smaller HV) was associated with increased BBB dysfunction within the hippocampus. Finally, to examine the potential clinical relevance of regional BBB dysfunction, we (iii) performed mediation analyses to examine whether WMH volume or HV mediated the potential associations between cognition and BBB dysfunction.

\section{Methods}

\subsection{Participants}

To obtain representative variation in $\mathrm{WMH}$ volume, $\mathrm{HV}$, and cognitive function across the spectrum from normal cognition to dementia, $\mathrm{CN}$ older individuals as well as memory clinic patients with various degrees of cognitive impairment were included in this study. Memory clinic patients who underwent standard clinical assessments (including a complete neuropsychological assessment) were recruited at the Maastricht University Medical Center and Zuyderland Medical Center Heerlen. CN controls were enrolled through an advertisement in the local newspaper and an online advertisement and underwent a similar neuropsychological assessment. For all participants, educational level (8-level scale; De Bie, 1987), medical history, and current medication were recorded. Raw scores on neuropsychological tests were converted to Z-scores, adjusted for age, sex, and education using normative data (Van der Elst et al., 2005; Van der Elst et al., 2006a; van der Elst et al., 2006b; Van der Elst et al., 2006c), and (objective) cognitive impairment was defined as Z-score $<-1.5$.

Inclusion criteria for patients were a clinical diagnosis of either MCI (Petersen, 2004) or clinical AD (McKhann et al., 2011) and a Mini-Mental State Examination (MMSE) score of $\geq 20$. Diagnosis of $\mathrm{MCI}$ was made when concern about cognitive functioning was reported by the patient or an informant, cognitive impairment was detected on at least one cognitive domain, and dementia was absent (Petersen, 2004). We did not aim to target $\mathrm{MCI}$ due to $\mathrm{AD}$ specifically as this study was not designed to measure BBB disruption as an (early) marker for AD. We were rather interested in including a heterogeneous sample of individuals with various amounts of cognitive impairment and variability in CSVD and neurodegenerative burden, and therefore we did not apply the NIAAA research criteria for $\mathrm{MCI}$ (Albert et al., 2011), but rather a clinical MCI diagnosis (Petersen, 2004). AD diagnosis was made when individuals met the NIA-AA core clinical criteria for AD (McKhann et al., 2011).

Besides the $\mathrm{MCI}$ and $\mathrm{AD}$ groups, we included a $\mathrm{CN}$ participant group, which included $\mathrm{CN}$ participants who were recruited through newspaper advertisements. These individuals had no cognitive complaints, had not visited a memory clinic, had no impairment in memory performance, and had an MMSE score of $\geq 27$. In addition, the $\mathrm{CN}$ group consisted of individuals who visited the memory clinic and had received a diagnosis of subjective cognitive decline (Jessen et al., 2014). These individuals reported self-experienced cognitive decline in comparison with a previously normal status and unrelated to an acute event, but no objective cognitive impairment was detected on any of the neuropsychological tests (Jessen et al., 2014).

Additional inclusion criteria for all participants were age $\geq$ 55 years and eligibility for undergoing 3 Tesla MRI and gadolinium contrast medium administration. Exclusion criteria for all participants included impaired renal function (estimated glomerular filtration rate $<30 \mathrm{~mL} / \mathrm{min}$ ), and presence of psychiatric or neurological disorders other than $\mathrm{AD}, \mathrm{cSVD}$, or non-invalidating stroke, that might be related to the cognitive impairment. Participants with structural abnormalities on MRI and those with recent (e.g., $<3$ months before inclusion) ischemic or hemorrhagic stroke were excluded.

Written informed consent was obtained from all participants before inclusion. This study was approved by the local institutional review boards and approved by the medical ethics committee in Maastricht.

\subsection{MR imaging}

Images were acquired on a 3.0 Tesla MRI system with a 32channel head coil (Philips, Achieva TX; Philips Healthcare, Best, the Netherlands). The imaging protocol was split into 2 sessions to reduce the burden of the long acquisition time and to minimize discomforts. During the first session, 3D T1-weighted gradient-echo (repetition time [TR] $8 \mathrm{~ms}$; echo time [TE] $4 \mathrm{~ms}$; flip angle $8^{\circ} ; 1 \mathrm{~mm}$ cubic voxel size) images were acquired for anatomical reference, 3D T2-weighted fluid attenuation inversion recovery (FLAIR; TR/TE/inversion time [TI] of 4800/290/1650 ms; $1 \mathrm{~mm}$ cubic voxel size) for determination of WMH volume, and multislice T2-weighted turbo spin echo and T2-weighted gradient-echo images with a section thickness of $5 \mathrm{~mm}$ in the transverse plane were acquired for detection of other tissue abnormalities (i.e., microbleeds, lacunar infarcts, hemorrhages and other infarcts). During the second session (median time between sessions 0 days, interquartile range $0-4$ days), dual-time resolution DCE-MRI was acquired (van de Haar et al., 2016; Zhang et al., 2017). The dual-time DCE-MRI protocol had a short dynamic scan time (3.2 seconds) during the steep signal changes in initial circulations of the contrast agent and longer scan times (dynamic scan time, 30.5 seconds) during the longer leakage phase with much slower signal changes. Before contrast administration, (precontrast) scans of both sequences were acquired. Subsequently, a bolus injection was administered during the fast sequence $(0.1 \mathrm{mmol} / \mathrm{kg}$ gadobutrol, Gadavist; Bayer AG, Leverkusen, Germany), intravenously in the antecubital vein (injection rate $3 \mathrm{~mL} / \mathrm{s}, 20 \mathrm{~mL}$ saline flush). The fast sequence consisted of 29 volumes (TR/TE 5.3/2.5 ms, voxel size $2 \times 2 \times 5 \mathrm{~mm}$ ), and the slow sequence consisted of 35 volumes (TR/TE 5.6/2.5 ms, voxel size $1 \times 1 \times 2 \mathrm{~mm}$ ). T1 mapping was performed before contrast administration and dynamic imaging to enable the conversion of the contrast-enhanced tissue signal intensities to concentrations (Larsson et al., 2009). 


\subsection{Brain region segmentation}

Automated software (FreeSurfer, version 5.1.0) was used with default settings as described previously (Fischl, 2012). The segmentation was visually checked by one author (W.M.F.), and manual adjustments were applied to correct for overestimation or underestimation of the GM/WM boundaries and to identify brain areas erroneously in or excluded during skull stripping. From the segmented brain regions, the estimated intracranial volume (ICV), overall GM volume (including cortical GM, deep GM [thalamus, caudate nucleus, putamen, pallidum, amygdala, and accumbens area], and hippocampus), HV, and total WM volume (including WMH) were extracted (Fischl, 2012).

WMH volume was semiautomatically determined using an inhouse developed, segmentation tool (GIANT) to differentiate between normal appearing white matter (NAWM) and WMH (Jacobs et al., 2014). Manual corrections were performed where necessary. The whole procedure was performed by a single rater (I.C.M.V.) who was trained until excellent inter-rater variability was achieved (intraclass correlation coefficient $>0.999$ ) on an independent practice set of scans $(n=20)$ that were also semiautomatically segmented by an experienced neuroradiologist. Total WMH volume was normalized to ICV. WMH volume was first divided by ICV, then multiplied by a factor 10,000 , and subsequently log-transformed to better approximate a normal distribution.

\subsection{Pharmacokinetic modeling and histogram analysis}

The vascular input function was extracted from manually selected voxels ( $n \sim 20$ ) within the superior sagittal sinus of each individual. Pharmacokinetic modeling was applied for each voxel using the Patlak graphical approach to obtain the local BBB leakage rate $\left(K_{i}\right.$ in minute ${ }^{-1}$ as the slope of the Patlak plot) (Patlak et al., 1983; van de Haar et al., 2016; Zhang et al., 2017). As leakage was very subtle, noisy Patlak graphs were obtained, which resulted in voxels with positive and negative $K_{i}$ values (van de Haar et al., 2016; van de Haar et al., 2017). To discern the measurable leakage from noise, a histogram analysis was applied to each investigated tissue region (van de Haar et al., 2016). The histograms were skewed to positive $K_{i}$ values, and the negative bins were subtracted from the positive part to exclude voxels in which no substantial leakage could be measured (van de Haar et al., 2016). Subsequently, the mean $\mathrm{K}_{\mathrm{i}}$ of all voxels within each region was calculated. The BBB leakage volume $\mathrm{V}_{\mathrm{l}}$ was calculated as the percentage of remaining voxels after the histogram subtraction out of the total number of voxels within a specified ROI, which is a similar approach to the one published previously (van de Haar et al., 2016). Note that after subtracting the part with negative $K_{i}$ values in the histogram, the mean $K_{i}$ remains the same as all voxels are considered, including the subtracted voxels for which $K_{i}$ was set to zero. This step differs from our previous study (van de Haar et al., 2016), as now all tissue voxels are included for the calculation of the leakage rate to represent the entire tissue region.

\subsection{Visual rating MRI markers of neurodegeneration and cerebrovascular damage}

Several MRI markers of cerebrovascular damage and neurodegeneration were visually rated by an experienced neuroradiologist (W.M.P.) who was blinded to the clinical data. Medial temporal lobe atrophy (MTA) was rated bilaterally on coronal T1-weighted images using a previously described rating scale (range $0-4$ for the average of left and right) (Scheltens et al., 1992). WMH load was scored according to the Fazekas scale (Fazekas et al., 1987). Lacunes were identified on FLAIR and T2-weighted spin echo images
(Wardlaw et al., 2013). Cerebral microbleeds were identified on T2weighted gradient-echo images in cortical or subcortical regions (Greenberg et al., 2009). Old cortical infarcts of $>15 \mathrm{~mm}$ in diameter were identified on T2-weighted spin echo and FLAIR images, and old cerebral hemorrhage was identified on T2-weighted gradient echo images.

\subsection{Neuropsychological assessment}

We focused on 2 cognitive outcomes in our analysis. Memory performance was evaluated because it is the primary cognitive domain that is affected in AD (Jahn, 2013), and information processing speed was chosen because of its previously reported close association with vascular cognitive impairment, in particular WMH (Wiseman et al., 2018). Memory performance was assessed with the 15-word verbal learning task (VLT) (Van der Elst et al., 2005), of which the delayed memory recall (VLTdr) (number of correctly recalled words after a 20-minute delay) was used as outcome measure. The letter-digit substitution test (LDST) was used to measure information processing speed, with the number of correct items used as outcome measure (van der Elst et al., 2006b).

\subsubsection{Additional neuropsychological assessment}

Additional neuropsychological tests were only used for diagnostic purpose and included memory performance measured as immediate (sum of the number of correctly recalled words directly after each of the 5 trials) memory recall according to the 15-word VLT (Van der Elst et al., 2005). Attention was measured using the average of the Stroop Color Word Test cards 1 and 2 (Stroop, 1935; Van der Elst et al., 2006c) and using the average of the concept shifting test part A and B (Van der Elst et al., 2006a). Executive functioning was measured using the interference index from the Stroop Color Word Test and the interference index from the concept shifting test (Stroop, 1935; Van der Elst et al., 2006a; Van der Elst et al., 2006c). These tests measured 2 components of executive functioning, sensitivity to interference, and concept shifting, respectively. The median [interquartile range] time between neuropsychological assessment and MRI acquisition was 3 [0-8] months. Z-scores on cognitive tests according to diagnostic group are outlined in Table 1.

\subsection{Vascular risk factor assessment and laboratory measurements}

Hypertension was defined as current use of antihypertensive medication, and hypercholesterolemia was defined as current use of cholesterol-lowering medication. Diabetes was defined as known history of diabetes type 1 or 2 and cardiovascular disease as known history of myocardial infarction, angina pectoris, and/or cardiac arrhythmia. Blood samples were collected and analyzed to measure hematocrit levels and renal function. Apolipoprotein E (ApoE) genotyping was performed using a method of polymerase chain reaction. Individuals with at least one $\varepsilon 4$ allele were classified as ApoE4 positive.

\subsection{Statistical analysis}

Differences in group characteristics were assessed using oneway analyses of variance with post hoc Tukey pairwise comparisons. Kruskal-Wallis tests with post hoc Dunn's pairwise comparisons were applied to assess group differences for data with a skewed distribution. Pearson chi-square or Fisher's exact tests were used to assess differences in proportions between groups for categorical variables. We ran regression models with BBB leakage as a dependent variable and age as an independent variable, corrected for diagnostic group. 
Table 1

Group characteristics according to diagnosis

\begin{tabular}{|c|c|c|c|c|}
\hline Participant characteristics & $\mathrm{CN}(\mathrm{n}=32)$ & $\mathrm{MCI}(\mathrm{n}=34)$ & $\operatorname{Dementia}^{g}(\mathrm{n}=14)$ & $p$-value \\
\hline Age (y), mean (SD) & $71.8(7.0)$ & $68.6(6.3)$ & $71.6(6.7)$ & 0.130 \\
\hline Male, n (\%) & $21(66)$ & $19(56)$ & $11(79)$ & 0.318 \\
\hline Education $(\text { level })^{\mathrm{f}}$ & $5.0[5.0,6.0]$ & $5.0[4.0,6.0]$ & $5.0[4.0,6.0]$ & 0.267 \\
\hline $\mathrm{eGFR}(\mathrm{mL} / \mathrm{min})$ & $75.0[69.6 ; 82.7]$ & $81.0[71.9 ; 89.2]$ & $74.0[69.8 ; 81.3]$ & 0.237 \\
\hline ApoE4 positive, $\mathrm{n}(\%)^{\mathrm{h}}$ & $13(42)$ & $12(36)$ & $8(57)$ & 0.419 \\
\hline Hypertension, n (\%) & $13(41)$ & $13(38)$ & $6(43)$ & 0.953 \\
\hline Hypercholesterolemia, n (\%) & $10(31)$ & $7(21)$ & $4(29)$ & 0.599 \\
\hline Diabetes mellitus, n (\%) & $1(3)$ & $5(15)$ & $2(14)$ & 0.216 \\
\hline Cardiovascular disease, n (\%) & $10(31)$ & $11(32)$ & $3(21)$ & 0.769 \\
\hline Hematocrit & $0.45[0.42 ; 0.46]$ & $0.43[0.42 ; 0.46]$ & $0.44[0.41 ; 0.48]$ & 0.452 \\
\hline \multicolumn{5}{|l|}{ Imaging characteristics } \\
\hline $\operatorname{ICV}\left(\mathrm{cm}^{3}\right)$ & $1432[1175 ; 1628]$ & $1503[1246 ; 1644]$ & $1601[1388 ; 1728]$ & 0.345 \\
\hline HV (\%ICV) & $0.52[0.45 ; 0.64]$ & $0.46[0.41 ; 0.54]$ & $0.39[0.36 ; 0.44]^{c, e}$ & 0.001 \\
\hline WMH volume (\%ICV) & $0.53[0.34 ; 0.67]$ & $0.65[0.41 ; 1.09]$ & $0.61[0.30 ; 0.95]$ & 0.319 \\
\hline LI present, n (\%) & $3(9)$ & $6(18)$ & $3(21)$ & 0.495 \\
\hline CMB presence, $\mathrm{n}(\%)$ & $1(3)$ & $6(18)$ & $3(21)$ & 0.078 \\
\hline IS present, $\mathrm{n}(\%)$ & $1(3)$ & $6(18)$ & $0(0)$ & 0.075 \\
\hline ICH present, n (\%) & $0(0)$ & $1(3)$ & $0(0)$ & 1.000 \\
\hline Fazekas score & $1.00[1.00 ; 2.00]$ & $1.00[1.00 ; 2.00]$ & $1.00[1.00 ; 1.75]$ & 0.861 \\
\hline Mean MTA & $0.50[0.00 ; 1.00]$ & $0.75[0.00 ; 1.38]$ & $1.50[0.62 ; 2.38]^{\mathrm{b}, \mathrm{d}}$ & 0.010 \\
\hline Contrast agent $(\mathrm{mL})$, mean (SD) & $7.6(1.2)$ & $7.5(1.3)$ & $7.6(1.3)$ & 0.970 \\
\hline \multicolumn{5}{|l|}{ Cognitive measures, raw scores } \\
\hline MMSE $^{\mathrm{h}}$ & $29.0[28.0 ; 30.0]$ & $27.0[26.0 ; 29.0]^{\mathrm{a}}$ & $24.5[21.0 ; 27.0]^{\mathrm{c}, \mathrm{e}}$ & $<0.001$ \\
\hline VLTdr, mean (SD) & $9.19(2.85)$ & $5.74(3.76)^{c}$ & $2.69(1.25)^{\mathrm{c}, \mathrm{d}}$ & $<0.001$ \\
\hline LDST, mean $(\mathrm{SD})^{\mathrm{h}}$ & $43.87(10.30)$ & $34.79(8.73)^{b}$ & $31.80(12.45)^{\mathrm{b}}$ & $<0.001$ \\
\hline \multicolumn{5}{|l|}{ Cognitive measures, Z-scores } \\
\hline VLT, mean (SD) & $0.64(1.15)$ & $-0.73^{\mathrm{c}}(1.22)$ & $-1.67^{\mathrm{c}}(1.43)$ & $<0.001$ \\
\hline VLT delayed, mean (SD) & $0.44(1.12)$ & $-1.08^{\mathrm{c}}(1.41)$ & $-2.07^{\mathrm{c}, \mathrm{d}}(0.81)$ & $<0.001$ \\
\hline LDST, mean $(S D)^{\mathrm{h}}$ & $0.54(0.91)$ & $-0.39^{\mathrm{c}}(0.78)$ & $-0.53^{\mathrm{b}}(1.08)$ & $<0.001$ \\
\hline Stroop $1+2^{\mathrm{h}}$ & $-0.08[-0.41 ; 0.52]$ & $-1.36^{\mathrm{C}}[-1.98 ;-0.67]$ & $-1.51^{\mathrm{b}}[-2.25 ;-0.56]$ & $<0.001$ \\
\hline $\operatorname{CST} 1+2^{\mathrm{h}}$ & $0.46[-0.10 ; 0.97]$ & $-0.54^{\mathrm{a}}[-1.62 ; 0.43]$ & $-0.54^{\mathrm{a}}[-1.87 ; 0.31]$ & 0.007 \\
\hline Stroop interference ${ }^{\mathrm{h}}$ & $0.84[-0.10 ; 1.27]$ & $-0.35^{\mathrm{b}}[-0.89 ; 0.19]$ & $-0.69^{\mathrm{b}}[-3.47 ; 0.21]$ & $<0.001$ \\
\hline CST interference $^{\mathrm{h}}$ & $0.41[-0.40 ; 0.86]$ & $-0.85[-1.90 ; 0.77]$ & $-2.74^{\mathrm{b}, \mathrm{d}}[-3.50 ;-2.33]$ & 0.001 \\
\hline
\end{tabular}

Values represent median [interquartile range] unless otherwise specified.

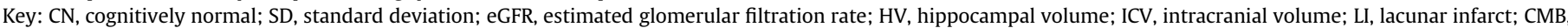

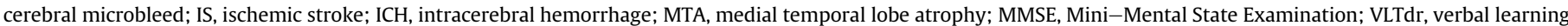
task delayed recall; LDST, letter-digit substitution test; CST, concept shifting test.

a $p<0.05$ versus $\mathrm{CN}$.

b $p<0.01$ versus $\mathrm{CN}$.

c $p<0.001$ versus $\mathrm{CN}$.

${ }^{\mathrm{d}} p<0.05$ versus $\mathrm{MCI}$.

e $p<0.01$ versus $\mathrm{MCI}$.

${ }^{f}$ Education level was based on an 8-level scale (De Bie, 1987).

g Neuropsychological data were missing for one case.

h Data were missing: MMSE, $\mathrm{n}=2$; ApoE4, $\mathrm{n}=1$; LDST, $\mathrm{n}=4$; Stroop $1+2, \mathrm{n}=3$, CST $1+2, \mathrm{n}=20$; CST interference, $\mathrm{n}=22 ;$ Stroop interference, $\mathrm{n}=4$.

We set out to investigate the relation between $\mathrm{WMH}$ volume and regional BBB integrity within the total GM and WM and within their subregions (cortical GM, deep GM, hippocampus, NAWM, and $\mathrm{WMH}$ ) using multivariable linear regression analyses. Normalized and log-transformed $\mathrm{WMH}$ volume was included as a dependent variable and regional leakage rate or volume (both cube root-transformed to better approximate a normal distribution) as an independent variable, corrected for age and diagnostic group (in all analyses diagnostic group was entered as a dummy variable, i.e., $\mathrm{MCI}=0$ or $1 ; \mathrm{AD}=0$ or 1 ). We applied a false discovery rate procedure (q-0.05) to correct for multiple comparisons over different brain tissue regions (Benjamini and Hochberg, 1995).

Next, we applied multivariable linear regression with HV (relative to ICV and log-transformed to better approximate a normal distribution) as a dependent variable and hippocampal BBB leakage (cube root-transformed) as an independent variable, with age and diagnostic group as covariates.

Two mediation models were run to test for direct and indirect associations between cognition and BBB leakage. The first model included information processing speed performance as a dependent variable, WM BBB leakage (cube root-transformed) as an independent variable, and WMH volume (normalized and log- transformed) as a mediator variable. The second model included memory performance as a dependent variable, hippocampal BBB leakage (cube root-transformed) as an independent variable, and HV (relative to ICV and log-transformed) as a mediator variable (Baron and Kenny, 1986). All analyses were corrected for age (at MRI), sex, educational level, time between MRI and neuropsychological assessment, and When statistically significant associations were present both in path a and path $b$, we tested the indirect mediating effect $\left(a^{*} b\right)$. The standard error parameters of the mediation models were bootstrapped, and the $95 \%$ confidence interval for each regression coefficient was calculated using the biascorrected and accelerated bootstrap method (Efron, 1987), which corrects for bias and skewness in the distribution of bootstrap estimates. The number of bootstrap samples in each analysis was set to 5000 . Because the sampling distribution of the indirect effect $\mathrm{a}^{*} \mathrm{~b}$ is highly skewed and the standard Z-method presumes a symmetric distribution, we reported the bias-corrected and accelerated 95\% confidence interval of any indirect effects and assumed the effect was significant if the confidence interval did not contain 0 (Williams and MacKinnon, 2008).

A threshold of $\alpha<0.05$ was used to determine statistical significance. All $p$-values are two-tailed. All analyses were conducted 
using the $\mathrm{R}$ statistical software (version 3.3.3; packages used include sjstats, lm.beta, compareGroups, lavaan, and boot; R Core Team, 2016)

\section{Results}

\subsection{Participant characteristics}

Eighty participants were included in the present study, consisting of $32 \mathrm{CN}$ controls, 34 with $\mathrm{MCI}$, and 14 with AD dementia. The group characteristics of the participants according to diagnostic group are summarized in Table 1. Individuals with MCI had lower scores on the MMSE, VLTdr, and LDST compared with the CN individuals. Individuals with dementia had lower scores on the MMSE and VLTdr, smaller HV, and higher MTA scores compared with the $\mathrm{MCI}$ and $\mathrm{CN}$ groups and lower scores on the LDST compared with the $\mathrm{CN}$ group. There was within- and between-subject variability in leakage rate and volume in all of the examined brain regions (Supplementary Tables $1 \mathrm{a}$ and $1 \mathrm{~b}$ ). Leakage rate and volume did not differ between groups and were not associated with age after correcting for diagnostic group.

\section{2. $W M H$ volume and $B B B$ leakage}

The associations between $\mathrm{WMH}$ volume and regional $\mathrm{BBB}$ leakage are provided in Table 2. In the total studied sample, WMH volume was positively associated with BBB leakage rate within the total GM and WM $\left(R^{2}>0.31\right)$ (Fig. 1). This association remained significant for BBB leakage within the cortex, deep GM, NAWM, and $\mathrm{WMH}$, but not within the hippocampus. The results were similar for the association between WMH volume and leakage volume.

\subsection{HV and BBB leakage}

HV was not significantly associated with BBB leakage within the hippocampus in the total sample (standardized beta coefficient [95\% confidence interval]) $\mathrm{K}_{\mathrm{i}}=0.14[-0.05,0.33], p=0.14 ; \mathrm{V}_{\mathrm{l}}=0.13$ $[-0.06,0.32], p=0.18)$.

\subsection{Cognitive performance and BBB leakage}

Results of the mediation model analyses are presented in Fig. 2 and Table 3. A direct effect was present between WM leakage rate and information processing speed. When WMH volume was added to the model, the mediating (i.e., indirect) effect of WMH volume was significant for the relation between leakage rate and information processing speed (B [95\% confidence interval] $=-222$ $[-541,-27])$, and the direct effect between leakage rate and information processing speed was no longer statistically significant.
In contrast, there were no direct or indirect effects between hippocampal leakage rate/volume and memory performance and between leakage volume and information processing speed.

\section{Discussion}

This study demonstrates that BBB leakage is associated with cognitive performance in individuals with CSVD across the clinical spectrum from normal cognition to dementia in a population with a mixture of $A D$ and cerebrovascular pathology. Although previous studies have already revealed BBB leakage in clinical populations with CSVD and $A D$, we now extend these findings by demonstrating for the first time that (i) BBB dysfunction throughout the whole brain is associated with CSVD, independent of cognitive state, (ii) BBB dysfunction is associated with impaired cognitive performance: information processing speed appears to be affected by WM BBB leakage in an indirect way, through mediation of $\mathrm{WMH}$, and (iii) local BBB dysfunction is not related to HV reduction, neither in $\mathrm{CN}$ controls nor in memory clinic patients. As such, in this population of patients, most of whom had cognitive impairment or dementia, BBB dysfunction may form an indirect pathophysiologic pathway to cognitive decline.

We observed that global BBB leakage within the GM and WM was positively associated with WMH volume. When we detailed this examination to subregions, we found that this association was apparent within the cortex, deep GM, NAWM, and WMH. Our findings are consistent with previous studies demonstrating positive associations between BBB leakage in WM and GM regions and cSVD using DCE-MRI (Wardlaw, 2010; Wardlaw et al., 2009, 2017; Zhang et al., 2017), supporting the idea that cSVD is a dynamic and progressive whole brain disease (Shi and Wardlaw, 2016). Our findings extend the existing literature by showing that BBB leakage plays a constant role in pathological CSVD processes across the spectrum from normal cognitive aging to Alzheimer-type dementia.

Hippocampal neurodegeneration is a critical feature of $A D$, but it is also associated with cerebrovascular damage (Freeze et al., 2017; Guzman et al., 2013; Kim et al., 2015). Previous work has demonstrated increased BBB leakage rate within the hippocampus in individuals with $\mathrm{MCI}$ compared with age-matched $\mathrm{CN}$ controls (Montagne et al., 2015). Actually, the same group recently reported an absence of an association between leakage and hippocampal volume (Nation et al., 2019). Our results are in line with this lack of an association between hippocampal leakage and HV, which suggests that HV loss may not be associated with BBB dysfunction in a direct way. BBB leakage might occur in parallel to or at an earlier stage in the development of hippocampal loss. Alternatively, it could well be that BBB leakage is more strongly associated with vascular pathology than neurodegenerative pathology and that our

Table 2

Associations between WMH volume and the regional BBB leakage measures leakage rate and volume

\begin{tabular}{|c|c|c|c|c|c|c|}
\hline \multirow{2}{*}{$\begin{array}{l}\text { Region of } \\
\text { interest }\end{array}$} & \multicolumn{3}{|c|}{ Leakage rate } & \multicolumn{3}{|c|}{ Leakage volume } \\
\hline & Beta-K $\mathrm{K}_{\mathrm{i}}$ & $95 \% \mathrm{CI}$ & $\overline{p \text {-value }}$ & $\overline{\text { Beta- }} \mathrm{V}_{\mathrm{l}}$ & $95 \% \mathrm{CI}$ & $\overline{p \text {-value }}$ \\
\hline Total GM & 0.22 & {$[0.03,0.41]$} & 0.029 & 0.23 & {$[0.03 ; 0.42]$} & 0.023 \\
\hline Total WM & 0.25 & {$[0.06 ; 0.44]$} & 0.010 & 0.24 & {$[0.05 ; 0.43]$} & 0.014 \\
\hline Cortex & 0.21 & {$[0.01 ; 0.40]$} & 0.039 & 0.22 & {$[0.02 ; 0.41]$} & 0.030 \\
\hline Deep GM & 0.22 & {$[0.03 ; 0.40]$} & 0.028 & 0.22 & {$[0.03 ; 0.41]$} & 0.028 \\
\hline Hippocampus & 0.12 & {$[-0.07 ; 0.32]$} & 0.223 & 0.11 & {$[-0.08 ; 0.31]$} & 0.264 \\
\hline NAWM & 0.25 & {$[0.06 ; 0.44]$} & 0.011 & 0.24 & {$[0.05 ; 0.43]$} & 0.016 \\
\hline WMH & 0.25 & {$[0.07 ; 0.44]$} & 0.010 & 0.27 & {$[0.08 ; 0.45]$} & 0.006 \\
\hline
\end{tabular}

Values represent standardized beta coefficients. Significant associations after false discovery rate correction are depicted in bold.

Key: CI, confidence interval; GM, gray matter; NAWM, normal appearing white matter; WM, white matter; WMH, white matter hyperintensities.

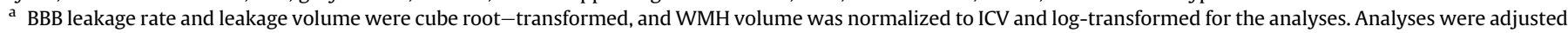
for age and diagnosis. 

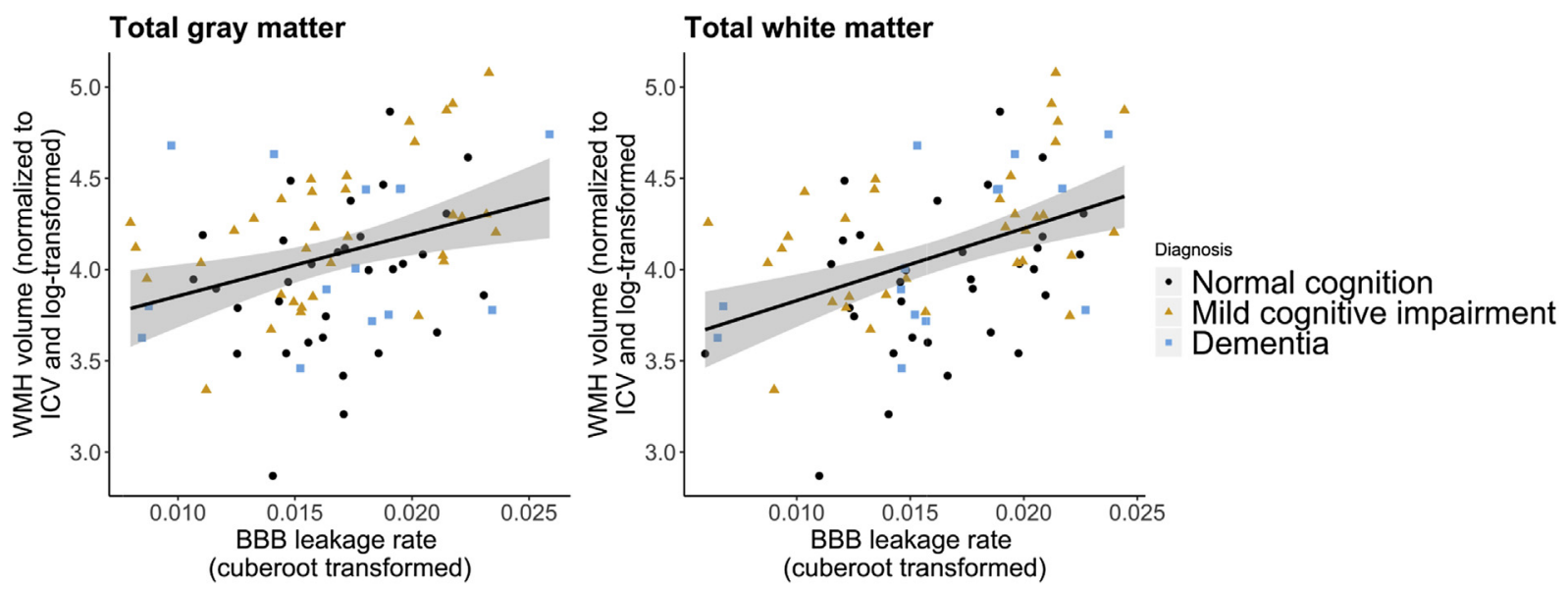

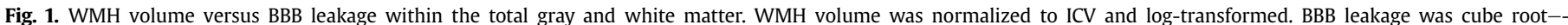

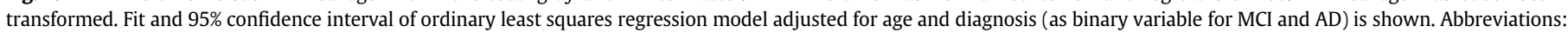
$\mathrm{AD}$, Alzheimer's disease; BBB, blood-brain barrier; ICV, intracranial volume; $\mathrm{MCI}$, mild cognitive impairment.

results were driven by the large proportion of individuals with vascular cognitive impairment.

Recently, the association between BBB integrity and AD has been topic of debate, attesting to the increasing awareness for the hypothesis that an interaction between vascular and AD pathology may play a role in the onset or progression of AD (Freeze et al., 2017; Sweeney et al., 2019). Three recent studies that applied DCE-MRI in $\mathrm{CN}$ individuals and patients with $\mathrm{MCI}$ and/or dementia found elevated BBB leakage in the patients compared with $\mathrm{CN}$ controls (Montagne et al., 2015; Nation et al., 2019; van de Haar et al., 2016). These studies confirm the importance of microvascular dysfunction in relation to cognitive status. One of these studies corrected for some markers of cerebrovascular damage in their analyses (van de
Haar et al., 2016). It remains unclear, however, whether the increased BBB dysfunction with MCI status observed by the other 2 studies from the same group (Montagne et al., 2015; Nation et al., 2019) was actually driven by increased cSVD pathology in cases with cognitive impairment compared with the controls.

To examine the clinical relevance of BBB dysfunction, we analyzed the observed association between BBB leakage and cognitive performance in more detail. Although there was no direct effect of BBB dysfunction on information processing speed after correcting for WMH volume, we identified an indirect association between WM BBB leakage rate and information processing speed that was mediated by WMH volume over the entire study population. Apart from 3 previous studies reporting a negative

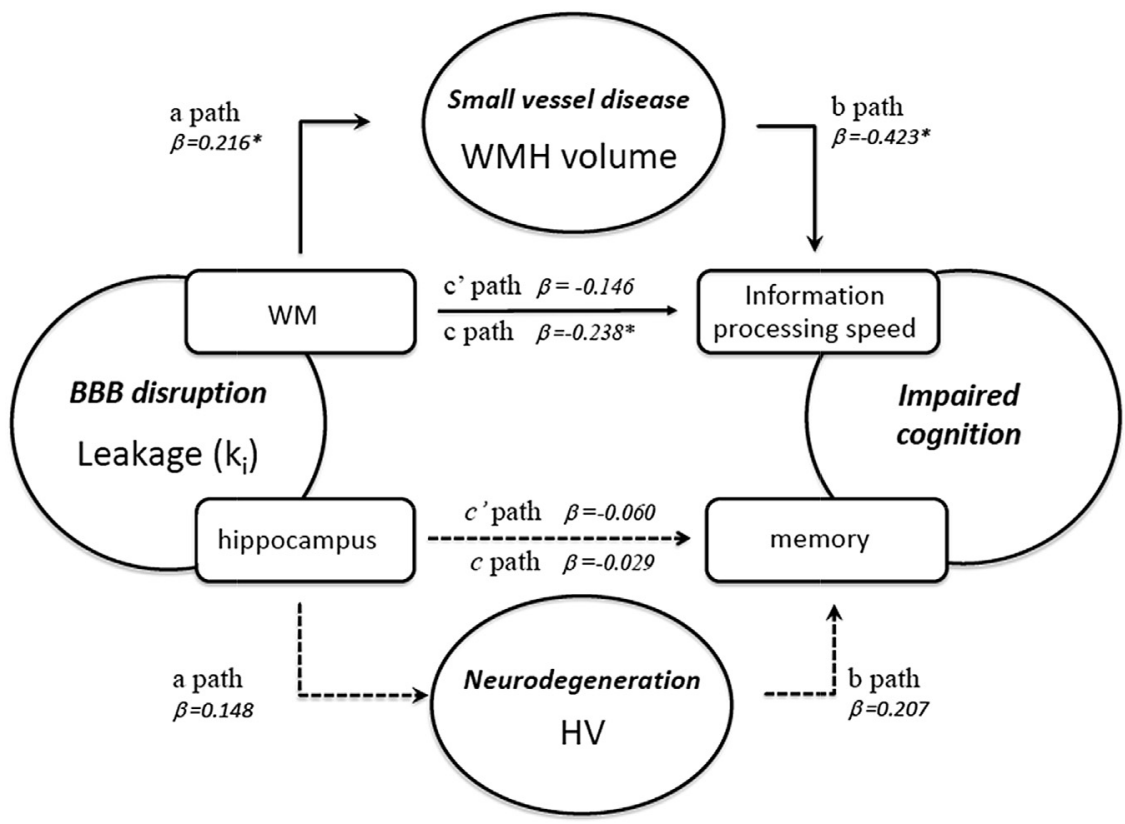

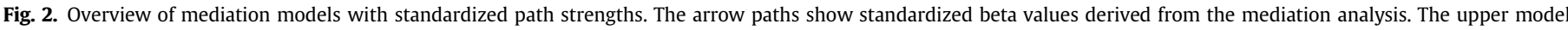

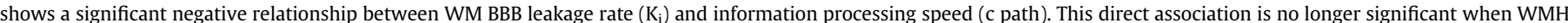

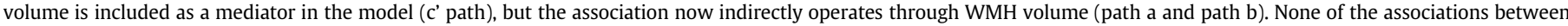

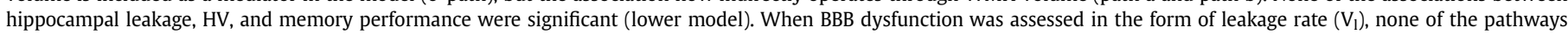

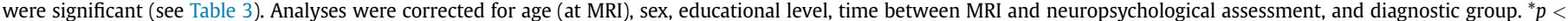
0.05. Abbreviations: BBB, blood-brain barrier; HV, hippocampal volume; MRI, magnetic resonance imaging; WM, white matter; WMH, white matter hyperintensity. 
Table 3

Mediation statistics

\begin{tabular}{|c|c|c|c|c|c|c|c|c|c|c|c|c|}
\hline \multirow[t]{4}{*}{ Leakage measure } & \multicolumn{12}{|c|}{ BBB leakage-memory performance relationships } \\
\hline & \multirow{2}{*}{\multicolumn{3}{|c|}{$\begin{array}{l}\text { Total effect } \\
\text { Direct c path } \\
\text { leakage } \rightarrow \text { memory }\end{array}$}} & \multicolumn{9}{|c|}{ Mediation model effects } \\
\hline & & & & \multicolumn{3}{|c|}{$\begin{array}{l}\text { Direct c' path } \\
\text { leakage } \rightarrow \text { memory }\end{array}$} & \multicolumn{3}{|c|}{$\begin{array}{l}\text { Mediation a path } \\
\text { leakage } \rightarrow \mathrm{HV}\end{array}$} & \multicolumn{3}{|c|}{$\begin{array}{l}\text { Mediation b path } \\
\mathrm{HV} \rightarrow \text { memory }\end{array}$} \\
\hline & $\bar{B}$ & Wald Z & $p$-value & $\bar{B}$ & Wald Z & $\overline{p \text {-value }}$ & $\overline{\mathrm{B}}$ & Wald Z & $\overline{p \text {-value }}$ & $\bar{B}$ & Wald Z & $\overline{p \text {-value }}$ \\
\hline $\begin{array}{l}\mathrm{K}_{\mathrm{i}} \\
{[95 \% \mathrm{Cl}]}\end{array}$ & $\begin{array}{l}-18.76 \\
{[-124.91,79.03]}\end{array}$ & -0.36 & 0.72 & $\begin{array}{c}-38.36 \\
{[-144.97}\end{array}$ & -0.71 & 0.48 & $\begin{array}{c}6.03 \\
{[-1.14}\end{array}$ & 1.69 & 0.09 & $\begin{array}{r}3.25 \\
{[-0.44}\end{array}$ & 1.72 & 0.09 \\
\hline \multirow[t]{5}{*}{$\begin{array}{l}\mathrm{V}_{\mathrm{I}} \\
{[95 \% \mathrm{Cl}]}\end{array}$} & $\begin{array}{c}-0.212 \\
{[-2.84,2.05]}\end{array}$ & -0.170 & 0.87 & $\begin{array}{c}-0.61 \\
{[-3.26,1 .}\end{array}$ & -0.47 & 0.64 & $\begin{array}{c}0.13 \\
{[-0.04}\end{array}$ & 1.51 & 0.13 & $\begin{array}{r}3.17 \\
{[-0.51}\end{array}$ & 1.67 & 0.10 \\
\hline & \multicolumn{12}{|c|}{ BBB leakage-information processing speed performance relationships } \\
\hline & \multicolumn{3}{|l|}{ Total effect } & \multicolumn{9}{|c|}{ Mediation model effects } \\
\hline & \multicolumn{3}{|l|}{$\begin{array}{l}\text { Direct c path } \\
\text { leakage } \rightarrow \text { IPS }\end{array}$} & \multicolumn{3}{|c|}{$\begin{array}{l}\text { Direct c' path } \\
\text { leakage } \rightarrow \text { IPS }\end{array}$} & \multicolumn{3}{|c|}{$\begin{array}{l}\text { Mediation a path } \\
\text { leakage } \rightarrow \text { WMH volume }\end{array}$} & \multicolumn{3}{|c|}{$\begin{array}{l}\text { Mediation b path } \\
\text { WMH volume } \rightarrow \text { IPS }\end{array}$} \\
\hline & $\bar{B}$ & Wald Z & $\overline{p \text {-value }}$ & $\overline{\mathrm{B}}$ & Wald Z & $\overline{p \text {-value }}$ & $\overline{\mathrm{B}}$ & Wald Z & $\overline{p \text {-value }}$ & $\overline{\mathrm{B}}$ & Wald Z & $p$-value \\
\hline $\begin{array}{l}\mathrm{K}_{\mathrm{i}} \\
{[95 \% \mathrm{Cl}]}\end{array}$ & $\begin{array}{l}-577.74 \\
{[-\mathbf{1 1 0 0 . 5 6},-\mathbf{4 0 . 8}}\end{array}$ & 6] & 0.03 & $\begin{array}{l}-355.26 \\
{[-899.35,}\end{array}$ & -1.33 & 0.19 & $\begin{array}{l}35.23 \\
{[1.07,}\end{array}$ & 1.98 & 0.048 & $\begin{array}{l}-6.31 \\
{[-9.33}\end{array}$ & ]$^{-3.84}$ & $<0.001$ \\
\hline $\begin{array}{l}\mathrm{V}_{1} \\
{[95 \% \mathrm{Cl}]}\end{array}$ & $\begin{array}{l}-10.75 \\
{[-22.50,1.11]}\end{array}$ & -1.79 & 0.07 & $\begin{array}{c}-6.11 \\
{[-17.70,5}\end{array}$ & -1.05 & 0.295 & $\begin{array}{c}0.74 \\
{[-0.04}\end{array}$ & 1.83 & 0.07 & $\begin{array}{l}-6.50 \\
{[-9.52}\end{array}$ & -4.10 & $<0.001$ \\
\hline
\end{tabular}

Mediation analyses were performed with bootstrap standard errors and bootstrap-based $p$-values. Confidence intervals were computed with bias-corrected and accelerated method. The number of bootstrap iterations was set to 5000. All models are corrected for age (at MRI), sex, educational level, time between MRI and neuropsychological assessment, and diagnostic group.

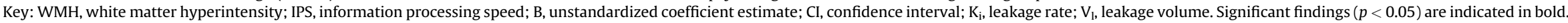


relationship between BBB leakage and global cognition (Nation et al., 2019; van de Haar et al., 2016; Wardlaw et al., 2017), this is the first study reporting associations between specific cognitive domains and BBB dysfunction. Our findings are consistent with previous work suggesting that BBB dysfunction in NAWM may eventually lead to cSVD pathology (Munoz Maniega et al., 2017). It can be hypothesized that BBB dysfunction throughout the brain is reflected by the amount of WMH burden and WMH burden in turn reflects WM damage, which is associated with decreases in processing speed (Baykara et al., 2016; Burns et al., 2005). Although decreases in processing speed are not a typical feature of $A D$, like decline in episodic memory, previous work has suggested that processing speed is an important component of cognition that influences performance on other cognitive domains (Salthouse, 2017). As such, BBB leakage could indirectly affect many cognitive domains through its effects on information processing speed. In contrast to information processing speed, we did not find a significant direct or indirect effect of hippocampal BBB leakage on memory performance. However, the sample size and pathological heterogeneity of the study population limit the ability to infer firm conclusions from these null findings.

\subsection{Study considerations}

The determined leakage measures are much lower than those from our previous study on early AD (van de Haar et al., 2016). This difference is due to the calculation of leakage rate over tissue regions with and without measurable leakage. However, in this study exactly the same analysis method was applied to all participants, and the associations were not affected by the type of analysis. Note that the leakage values as measured by DCE-MRI are not full quantitative physiologic measures and have been reported to vary between research sites, research studies, scan protocols, methods of data analysis, and study populations, which prompts the need for standardization and harmonization (Barnes et al., 2016; Raja et al., 2017; van de Haar et al., 2017). Furthermore, in this study, we tagged WMH volume as a proxy for cSVD severity. Although this may be a proxy for deeper/periventricular WMH (especially confluent WMH), previous studies have shown that punctate WMH in posterior brain regions may correspond to (Wallerian) degenerative processes in the context of AD pathology (Gold et al., 2012; McAleese et al., 2017; Riphagen et al., 2018). As such, the etiology of WMH may actually be of heterogeneous nature and differences may exist across diagnostic groups and brain regions. Therefore, we cannot rule out that besides the well-established association between BBB leakage and CSVD, BBB leakage in our study population may be, at least partly, associated with $\mathrm{AD}$-related $\mathrm{WMH}$ of neurodegenerative etiology.

\subsection{Study limitations}

The individual diagnostic groups have a limited sample size and were composed of individuals with clinical and pathological heterogeneity. Knowing this, we took a continuous analytical approach by examining the entire study population as a whole while correcting for clinical diagnosis in all analyses (to control for group effects) and by limiting the number of tests to 2 specific a priori hypotheses when we examined the association between BBB leakage and cognition. Because this was an exploratory study we did not correct for multiple comparisons. In addition to the statistical limitations, the studied sample is probably subject to selection bias and not fully representative of the actual population because individuals with comorbid disease conditions were probably less likely to participate in this research. Further selection bias may have occurred because the inclusion of memory clinic patients and controls was performed through different recruitment channels (newspaper vs. memory clinic). Another point of consideration is that the measurement of BBB leakage within smaller regions of interest such as the hippocampus is more prone to noise, measurement error, and partial volume effects of signal from structures such as the choroid plexus or meninges cannot be fully ruled out. Another limitation of this study is that AD biomarkers amyloid-beta and tau were unknown. Although AD-type dementia diagnosis was established according to the NIA-AA guidelines, the diagnosis was not confirmed with amyloid biomarker evidence. However, the positive predictive value of the clinical diagnosis of probable $A D$ is 83\% (Beach et al., 2012) and the prevalence of amyloid positivity in clinically diagnosed AD patients with ApoE e4 carrier status has been estimated at 95\% (95\% confidence interval, 90-96) (Ossenkoppele et al., 2015). Because amyloid-beta and tau levels were unknown, we were not able to assess associations between BBB leakage and these variables or to control for them in our analyses, but interesting recent work showed that BBB leakage is not related to these markers (McAleese et al., 2019; Nation et al., 2019). Although mediation implies a causal process, our data are of crosssectional nature and we are unable to conclude whether the associations are cause-effect.

\subsection{Future directions}

Future studies are needed to determine the associations between BBB dysfunction and AD biomarkers (amyloid-beta and tau) and/or imaging of the integrity of the myelin sheath while accounting for the effects of cerebrovascular pathology. Such studies should take into consideration the possible heterogeneous etiology of WMH (cSVD vs. neurodegenerative) located in different brain regions and diagnostic groups. In addition, future studies in larger patient groups should assess whether there are differential regional patterns of BBB leakage across the 2 main types of cSVD, namely cerebral amyloid angiopathy and hypertensive arteriopathy. Longitudinal studies could possibly shed more light on the temporal evolution of BBB dysfunction in the context of cSVD, neurodegeneration, and cognitive decline. Our findings suggest that the development of treatment strategies that improve cerebrovascular health, in particular by enhancing BBB integrity, may slow down deterioration in information processing speed in memory clinic patients.

\section{Conclusions}

This study shows that BBB dysfunction throughout the whole brain is related to cSVD severity in a cross-sectional study sample of older individuals ranging from normal cognition to clinical dementia. BBB dysfunction negatively and independently affects information processing speed performance through WMH pathology.

\section{Disclosure}

The authors have no actual or potential conflicts of interest.

\section{Acknowledgements}

This study was financially supported by a research grant [WE03-2012-40] by Alzheimer Nederland and Stichting 2Bike4Alzheimer. We would like to thank all participants and their caregivers for participation in this study. We thank Mark van Buchem and Matthijs van Osch for their contribution to the funding acquisition. We thank Danique Hellebrekers, Tiny Simons, Olin Jansen, and Rebecca Palm for their assistance in participant inclusion, Paul Hofman, Harm van de Haar, Sau May Wong, Jos Slenter, and Jan 
Jungerius for their contribution to the image analyses, and Saartje Burgmans for her help with the funding acquisition and study setup.

\section{Appendix A. Supplementary data}

Supplementary data to this article can be found online at https:// doi.org/10.1016/j.neurobiolaging.2019.09.017.

\section{References}

Albert, M.S., DeKosky, S.T., Dickson, D., Dubois, B., Feldman, H.H., Fox, N.C., Gamst, A. Holtzman, D.M., Jagust, W.J., Petersen, R.C., Snyder, P.J., Carrillo, M.C., Thies, B., Phelps, C.H., 2011. The diagnosis of mild cognitive impairment due to Alzheimer's disease: recommendations from the National Institute on Aging-Alzheimer's Association workgroups on diagnostic guidelines for Alzheimer's disease. Alzheimers Dement. 7, 270-279.

Arvanitakis, Z., Capuano, A.W., Leurgans, S.E., Bennett, D.A., Schneider, J.A., 2016. Relation of cerebral vessel disease to Alzheimer's disease dementia and cognitive function in elderly people: a cross-sectional study. Lancet Neurol. 15 , 934-943.

Barnes, S.R., Ng, T.S., Montagne, A., Law, M., Zlokovic, B.V., Jacobs, R.E., 2016. Optimal acquisition and modeling parameters for accurate assessment of low Ktrans blood-brain barrier permeability using dynamic contrast-enhanced MRI. Magn. Reson. Med. 75, 1967-1977.

Baron, R.M., Kenny, D.A., 1986. The moderator-mediator variable distinction in social psychological research: conceptual, strategic, and statistical considerations. J. Pers. Soc. Psychol. 51, 1173-1182.

Baykara, E., Gesierich, B., Adam, R., Tuladhar, A.M., Biesbroek, J.M., Koek, H.L., Ropele, S., Jouvent, E., Chabriat, H., Ertl-Wagner, B., Ewers, M., Schmidt, R., de Leeuw, F.E., Biessels, G.J., Dichgans, M., Duering, M., 2016. A novel imaging marker for small vessel disease based on Skeletonization of white matter tracts and diffusion histograms. Ann. Neurol. 80, 581-592.

Beach, T.G., Monsell, S.E., Phillips, L.E., Kukull, W., 2012. Accuracy of the clinical diagnosis of Alzheimer disease at national institute on aging Alzheimer disease centers, 2005-2010. J. Neuropathol. Exp. Neurol. 71, 266-273.

Benjamini, Y., Hochberg, Y., 1995. Controlling the false discovery rate: a practical and powerful approach to multiple testing. J. R. Stat. Soc. Series. B. Methodol. 57, 289-300.

Burns, J.M., Church, J.A., Johnson, D.K., Xiong, C., Marcus, D., Fotenos, A.F., Snyder, A.Z., Morris, J.C., Buckner, R.L., 2005. White matter lesions are prevalent but differentially related with cognition in aging and early Alzheimer disease. Arch. Neurol. 62, 1870-1876.

De Bie, S., 1987. Standaardvragen 1987: Voorstellen voor uniformering van vraagstellingen naar achtergrondkenmerken en interviews [Standard questions 1987: Proposal for uniformization of questions regarding background variables and interviews]. Leiden University Press, Leiden.

Efron, B., 1987. Better bootstrap confidence intervals. J. Am. Stat. Assoc. 82, 171-185.

Fazekas, F., Chawluk, J.B., Alavi, A., Hurtig, H.I., Zimmerman, R.A., 1987. MR signal abnormalities at $1.5 \mathrm{~T}$ in Alzheimer's dementia and normal aging. AJR Am. J. Roentgenol. 149, 351-356.

Fischl, B., 2012. Freesurfer. Neuroimage 62, 774-781.

Freeze, W.M., Jacobs, H.I., Gronenschild, E.H., Jansen, J.F., Burgmans, S., Aalten, P., Clerx, L., Vos, S.J., van Buchem, M.A., Barkhof, F., van der Flier, W.M., Verbeek, M.M., Rikkert, M.O., Backes, W.H., Verhey, F.R., 2017. White matter hyperintensities potentiate hippocampal volume reduction in non-demented older individuals with abnormal amyloid-beta. J. Alzheimers Dis. 55, 333-342.

Gold, B.T., Johnson, N.F., Powell, D.K., Smith, C.D., 2012. White matter integrity and vulnerability to Alzheimer's disease: preliminary findings and future directions. Biochim. Biophys. Acta 1822, 416-422.

Greenberg, S.M., Vernooij, M.W., Cordonnier, C., Viswanathan, A., Al-Shahi Salman, R., Warach, S., Launer, L.J., Van Buchem, M.A., Breteler, M.M., 2009. Cerebral microbleeds: a guide to detection and interpretation. Lancet Neurol. 8, 165-174.

Guzman, V.A., Carmichael, O.T., Schwarz, C., Tosto, G., Zimmerman, M.E., Brickman, A.M., 2013. White matter hyperintensities and amyloid are independently associated with entorhinal cortex volume among individuals with mild cognitive impairment. Alzheimers Dement. 9 (5 Suppl), S124-S131.

Iadecola, C., 2017. The neurovascular unit coming of age: a journey through neurovascular coupling in health and disease. Neuron 96, 17-42.

Iturria-Medina, Y. Sotero, R.C., Toussaint, P.J., Mateos-Perez, J.M., Evans, A.C., 2016. Early role of vascular dysregulation on late-onset Alzheimer's disease based on multifactorial data-driven analysis. Nat. Commun. 7, 11934.

Jack Jr., C.R., Knopman, D.S., Jagust, W.J., Petersen, R.C., Weiner, M.W., Aisen, P.S., Shaw, L.M., Vemuri, P., Wiste, H.J., Weigand, S.D., Lesnick, T.G., Pankratz, V.S., Donohue, M.C., Trojanowski, J.Q., 2013. Tracking pathophysiological processes in Alzheimer's disease: an updated hypothetical model of dynamic biomarkers. Lancet Neurol. 12, 207-216.

Jacobs, H.I., Clerx, L., Gronenschild, E.H., Aalten, P., Verhey, F.R., 2014. White matter hyperintensities are positively associated with cortical thickness in Alzheimer's disease. J. Alzheimers Dis. 39, 409-422.
Jahn, H., 2013. Memory loss in Alzheimer's disease. Dialogues Clin. Neurosci. 15 445-454.

Jessen, F., Amariglio, R.E., van Boxtel, M., Breteler, M., Ceccaldi, M., Chetelat, G. Dubois, B., Dufouil, C., Ellis, K.A., van der Flier, W.M., Glodzik, L., van Harten, A.C. de Leon, M.J., McHugh, P., Mielke, M.M., Molinuevo, J.L., Mosconi, L., Osorio, R.S. Perrotin, A., Petersen, R.C., Rabin, L.A., Rami, L., Reisberg, B., Rentz, D.M., Sachdev, P.S., de la Sayette, V., Saykin, A.J., Scheltens, P., Shulman, M.B. Slavin, M.J., Sperling, R.A., Stewart, R., Uspenskaya, O., Vellas, B., Visser, P.J., Wagner, M., 2014. A conceptual framework for research on subjective cognitive decline in preclinical Alzheimer's disease. Alzheimers Dement. 10, 844-852.

Kester, M.I., Goos, J.D., Teunissen, C.E., Benedictus, M.R., Bouwman, F.H. Wattjes, M.P., Barkhof, F., Scheltens, P., van der Flier, W.M., 2014. Associations between cerebral small-vessel disease and Alzheimer disease pathology as measured by cerebrospinal fluid biomarkers. JAMA Neurol. 71, 855-862.

Kim, G.H., Lee, J.H., Seo, S.W., Kim, J.H., Seong, J.K., Ye, B.S., Cho, H., Noh, Y., Kim, H.J. Yoon, C.W., Oh, S.J., Kim, J.S., Choe, Y.S., Lee, K.H., Kim, S.T., Hwang, J.W. Jeong, J.H., Na, D.L., 2015. Hippocampal volume and shape in pure subcortical vascular dementia. Neurobiol. Aging 36, 485-491.

Larsson, H.B., Courivaud, F., Rostrup, E., Hansen, A.E., 2009. Measurement of brain perfusion, blood volume, and blood-brain barrier permeability, using dynamic contrast-enhanced T(1)-weighted MRI at 3 tesla. Magn. Reson. Med, 62, 1270-1281.

McAleese, K.E., Graham, S., Dey, M., Walker, L., Erskine, D., Johnson, M., Johnston, E. Thomas, A.J., McKeith, I.G., DeCarli, C., Attems, J., 2019. Extravascular fibrinogen in the white matter of Alzheimer's disease and normal aged brains: implications for fibrinogen as a biomarker for Alzheimer's disease. Brain Pathol. 29, 414-424.

McAleese, K.E., Walker, L., Graham, S., Moya, E.L.J., Johnson, M., Erskine, D. Colloby, S.J., Dey, M., Martin-Ruiz, C., Taylor, J.P., Thomas, A.J., McKeith, I.G., De Carli, C. Attems, J., 2017. Parietal white matter lesions in Alzheimer's disease are associated with cortical neurodegenerative pathology, but not with small vesse disease. Acta Neuropathol. 134, 459-473.

McKhann, G.M., Knopman, D.S., Chertkow, H., Hyman, B.T., Jack Jr., C.R., Kawas, C.H., Klunk, W.E., Koroshetz, W.J., Manly, J.J., Mayeux, R., Mohs, R.C., Morris, J.C., Rossor, M.N., Scheltens, P., Carrillo, M.C., Thies, B., Weintraub, S., Phelps, C.H., 2011. The diagnosis of dementia due to Alzheimer's disease: recommendations from the National Institute on Aging-Alzheimer's Association workgroups on diagnostic guidelines for Alzheimer's disease. Alzheimers Dement. 7, 263-269.

Montagne, A., Barnes, S.R., Sweeney, M.D., Halliday, M.R., Sagare, A.P., Zhao, Z Toga, A.W., Jacobs, R.E., Liu, C.Y., Amezcua, L., Harrington, M.G., Chui, H.C., Law, M., Zlokovic, B.V., 2015. Blood-brain barrier breakdown in the aging human hippocampus. Neuron 85, 296-302.

Munoz Maniega, S., Chappell, F.M., Valdes Hernandez, M.C., Armitage, P.A. Makin, S.D., Heye, A.K., Thrippleton, M.J., Sakka, E., Shuler, K., Dennis, M.S. Wardlaw, J.M., 2017. Integrity of normal-appearing white matter: influence of age, visible lesion burden and hypertension in patients with small-vessel disease. J. Cereb. Blood Flow Metab. 37, 644-656.

Nation, D.A., Sweeney, M.D., Montagne, A., Sagare, A.P., D'Orazio, L.M., Pachicano, M. Sepehrband, F., Nelson, A.R., Buennagel, D.P., Harrington, M.G., Benzinger, T.L.S. Fagan, A.M., Ringman, J.M., Schneider, L.S., Morris, J.C., Chui, H.C., Law, M., Toga, A.W., Zlokovic, B.V., 2019. Blood-brain barrier breakdown is an early biomarker of human cognitive dysfunction. Nat. Med. 25, 270-276.

Ossenkoppele, R., Jansen, W.J., Rabinovici, G.D., Knol, D.L., van der Flier, W.M., van Berckel, B.N., Scheltens, P., Visser, P.J., Verfaillie, S.C., Zwan, M.D., Adriaanse, S.M., Lammertsma, A.A., Barkhof, F., Jagust, W.J., Miller, B.L., Rosen, H.J., Landau, S.M., Villemagne, V.L., Rowe, C.C., Lee, D.Y., Na, D.L., Seo, S.W., Sarazin, M., Roe, C.M., Sabri, O., Barthel, H., Koglin, N., Hodges, J., Leyton, C.E., Vandenberghe, R., van Laere, K., Drzezga, A., Forster, S., Grimmer, T., Sanchez-Juan, P., Carril, J.M., Mok, V., Camus, V., Klunk, W.E., Cohen, A.D., Meyer, P.T., Hellwig, S., Newberg, A. Frederiksen, K.S., Fleisher, A.S., Mintun, M.A., Wolk, D.A., Nordberg, A Rinne, J.O., Chetelat, G., Lleo, A., Blesa, R., Fortea, J., Madsen, K., Rodrigue, K.M., Brooks, D.J., 2015. Prevalence of amyloid PET positivity in dementia syndromes: a meta-analysis. JAMA 313, 1939-1949.

Patlak, C.S., Blasberg, R.G., Fenstermacher, J.D., 1983. Graphical evaluation of bloodto-brain transfer constants from multiple-time uptake data. J. Cereb. Blood Flow Metab. 3, 1-7.

Petersen, R.C., 2004. Mild cognitive impairment as a diagnostic entity. J. Intern. Med. 256, 183-194.

R Core Team, 2016. R: A Language and Environment for Statistical Computing. R Foundation for Statistical Computing, Vienna, Austria.

Raja, R., Rosenberg, G.A., Caprihan, A., 2017. MRI measurements of Blood-Brain Barrier function in dementia: a review of recent studies. Neuropharmacology 134, 259-271.

Riphagen, J.M., Gronenschild, E., Salat, D.H., Freeze, W.M., Ivanov, D., Clerx, L. Verhey, F.R.J., Aalten, P., Jacobs, H.I.L., 2018. Shades of white: diffusion properties of T1- and FLAIR-defined white matter signal abnormalities differ in stages from cognitively normal to dementia. Neurobiol. Aging 68, 48-58.

Salthouse, T.A., 2017. Shared and unique influences on age-related cognitive change Neuropsychology 31, 11-19.

Scheltens, P., Leys, D., Barkhof, F., Huglo, D., Weinstein, H.C., Vermersch, P., Kuiper, M., Steinling, M., Wolters, E.C., Valk, J., 1992. Atrophy of medial temporal lobes on MR in "probable" Alzheimer's disease and normal ageing: diagnostic value and neuropsychological correlates. J. Neurol. Neurosurg. Psychiatry 55, 967-972.

Schneider, J.A., Arvanitakis, Z., Bang, W., Bennett, D.A., 2007. Mixed brain pathologies account for most dementia cases in community-dwelling older persons. Neurology 69, 2197-2204.

Shi, Y., Wardlaw, J.M., 2016. Update on cerebral small vessel disease: a dynamic whole-brain disease. Stroke Vasc. Neurol. 1, 83-92. 
Stroop, J.R., 1935. Studies of interference in serial verbal reactions. J. Exp. Psychol. 18, $643-662$.

Sweeney, M.D., Montagne, A., Sagare, A.P., Nation, D.A., Schneider, L.S., Chui, H.C., Harrington, M.G., Pa, J., Law, M., Wang, D.J.J., Jacobs, R.E., Doubal, F.N., Ramirez, J., Black, S.E., Nedergaard, M., Benveniste, H., Dichgans, M., Iadecola, C., Love, S., Bath, P.M., Markus, H.S., Salman, R.A., Allan, S.M., Quinn, T.J., Kalaria, R.N., Werring, D.J., Carare, R.O., Touyz, R.M., Williams, S.C.R., Moskowitz, M.A., Katusic, Z.S., Lutz, S.E., Lazarov, O., Minshall, R.D., Rehman, J., Davis, T.P., Wellington, C.L., Gonzalez, H.M., Yuan, C., Lockhart, S.N., Hughes, T.M., Chen, C.L.H., Sachdev, P., O'Brien, J.T., Skoog, I., Pantoni, L., Gustafson, D.R., Biessels, G.J., Wallin, A., Smith, E.E., Mok, V., Wong, A., Passmore, P., Barkof, F., Muller, M., Breteler, M.M.B., Roman, G.C., Hamel, E., Seshadri, S., Gottesman, R.F., van Buchem, M.A., Arvanitakis, Z., Schneider, J.A., Drewes, L.R., Hachinski, V., Finch, C.E., Toga, A.W., Wardlaw, J.M., Zlokovic, B.V., 2019. Vascular dysfunction-The disregarded partner of Alzheimer's disease. Alzheimers Dement. 15, $158-167$.

van de Haar, H.J., Burgmans, S., Jansen, J.F., van Osch, M.J., van Buchem, M.A., Muller, M., Hofman, P.A., Verhey, F.R., Backes, W.H., 2016. Blood-brain barrier leakage in patients with early Alzheimer disease. Radiology 281, $527-535$.

van de Haar, H.J., Jansen, J.F.A., Jeukens, C., Burgmans, S., van Buchem, M.A., Muller, M., Hofman, P.A.M., Verhey, F.R.J., van Osch, M.J.P., Backes, W.H., 2017. Subtle blood-brain barrier leakage rate and spatial extent: considerations for dynamic contrast-enhanced MRI. Med. Phys. 44, 4112-4125.

Van der Elst, W., van Boxtel, M.P., van Breukelen, G.J., Jolles, J., 2005. Rey's verbal learning test: normative data for 1855 healthy participants aged 24-81 years and the influence of age, sex, education, and mode of presentation. J. Int. Neuropsychol. Soc. 11, 290-302.

Van der Elst, W., Van Boxtel, M.P., Van Breukelen, G.J., Jolles, J., 2006a. The Concept Shifting Test: adult normative data. Psychol. Assess. 18, 424-432.

van der Elst, W., van Boxtel, M.P., van Breukelen, G.J., Jolles, J., 2006b. The Letter Digit Substitution Test: normative data for 1,858 healthy participants aged 2481 from the Maastricht Aging Study (MAAS): influence of age, education, and sex. J. Clin. Exp. Neuropsychol. 28, 998-1009.
Van der Elst, W., Van Boxtel, M.P., Van Breukelen, G.J., Jolles, J., 2006c. The Stroop color-word test: influence of age, sex, and education; and normative data for a large sample across the adult age range. Assessment 13, 62-79.

Wardlaw, J.M., 2010. Blood-brain barrier and cerebral small vessel disease. J. Neurol. Sci. 299, 66-71.

Wardlaw, J.M., Doubal, F., Armitage, P., Chappell, F., Carpenter, T., Munoz Maniega, S. Farrall, A., Sudlow, C., Dennis, M., Dhillon, B., 2009. Lacunar stroke is associated with diffuse blood-brain barrier dysfunction. Ann. Neurol. 65, 194-202.

Wardlaw, J.M., Makin, S.J., Valdés Hernández, M.C., Armitage, P.A., Heye, A.K. Chappell, F.M. Muñoz-Maniega, S., Sakka, E., Shuler, K., Dennis, M.S. Thrippleton, M.J., 2017. Blood-brain barrier failure as a core mechanism in cerebral small vessel disease and dementia: evidence from a cohort study. Alzheimers Dement. 13, 634-643.

Wardlaw, J.M., Smith, E.E., Biessels, G.J., Cordonnier, C., Fazekas, F., Frayne, R. Lindley, R.I., O'Brien, J.T., Barkhof, F., Benavente, O.R., Black, S.E., Brayne, C., Breteler, M., Chabriat, H., Decarli, C., de Leeuw, F.E., Doubal, F., Duering, M. Fox, N.C., Greenberg, S., Hachinski, V., Kilimann, I., Mok, V., Oostenbrugge, R. Pantoni, L., Speck, O., Stephan, B.C., Teipel, S., Viswanathan, A., Werring, D., Chen, C., Smith, C., van Buchem, M., Norrving, B., Gorelick, P.B., Dichgans, M. 2013. Neuroimaging standards for research into small vessel disease and its contribution to ageing and neurodegeneration. Lancet Neurol. 12, 822-838.

Williams, J., MacKinnon, D.P., 2008. Resampling and distribution of the product methods for testing indirect effects in complex models. Struct. Equ. Modeling. 15, 23-51.

Wiseman, S.J., Booth, T., Ritchie, S.J., Cox, S.R., Munoz Maniega, S., Valdes Hernandez, M.D.C., Dickie, D.A., Royle, N.A., Starr, J.M., Deary, I.J., Wardlaw, J.M., Bastin, M.E., 2018. Cognitive abilities, brain white matter hyperintensity volume and structural network connectivity in older age. Hum. Brain Mapp. 39, 622-632.

Yamazaki, Y., Kanekiyo, T., 2017. Blood-brain barrier dysfunction and the pathogenesis of Alzheimer's disease. Int. J. Mol. Sci. 18, 1965.

Zhang, C.E., Wong, S.M., van de Haar, H.J., Staals, J., Jansen, J.F., Jeukens, C.R. Hofman, P.A., van Oostenbrugge, R.J., Backes, W.H., 2017. Blood-brain barrie leakage is more widespread in patients with cerebral small vessel disease. Neurology 88, 426-432.

Zlokovic, B.V., 2008. The blood-brain barrier in health and chronic neurodegenerative disorders. Neuron 57, 178-201. 